\title{
RELACIONAMENTO ENTRE PERSISTÊNCIA DO LUCRO RESIDUAL E PARTICIPAÇÃO DE MERCADO EM FIRMAS BRASILEIRAS DE CAPITAL ABERTO
}

\author{
ANTONIO CARLOS DIAS COELHO \\ Doutor em Controladoria e Contabilidade pela \\ Universidade de São Paulo \\ Professor Associado da Universidade Federal do Ceará \\ E-mail: acarloscoelho@terra.com.br
}

\author{
ANDSON BRAGA DE AGUIAR \\ Doutorando em Contabilidade pela \\ Universidade de São Paulo \\ Pesquisador do Laboratório de Pesquisas \\ em Práticas Gerenciais da Universidade de São Paulo \\ E-mail: abraga@usp.br
}

\section{Resumo}

Este estudo analisa a Dinâmica Informacional Linear (DIL) de Ohlson, avaliando os efeitos da participação de mercado de firmas brasileiras sobre a série de lucros residuais. Lucro residual é estimado a partir do modelo de avaliação da firma de Ohlson (1995). A participação de mercado é ponderada pela representatividade do setor em relação à média dos setores. São utilizadas três variáveis de controle: índice de concentração industrial, crescimento do PIB e porte da firma. Testa-se a hipótese de que participação de mercado, em firmas brasileiras, tem um relacionamento temporal significante estatisticamente em sua série de lucros residuais, mantida a persistência da DIL de Ohlson. A amostra é coletada a partir da base de dados do Economática, incluindo o período de 1996 - 2005. Os resultados demonstram que a premissa da DIL foi confirmada enquanto que a participação de mercado não apresenta conteúdo informacional, pois seu coeficiente $(B)$ não é estatisticamente significante em todos os modelos processados. Diante desses resultados, rejeita-se a hipótese de pesquisa. Conclui-se que a participação de mercado, conforme mensurada neste estudo, não provoca ganhos anormais em firmas brasileiras a partir da análise de seus lucros residuais.

Palavras-chave: persistência do lucro residual; Modelo de Ohlson; análise fundamentalista.

\section{Abstract}

This study seeks to analyze Ohlson's Linear Information Dynamics, evaluating the effect of Brazilian firm in the market over residual income series. Residual income is estimated from Ohlson's (1995) firm evaluation model. The share in the market is pondered by the representativity of the sector in relation to the sector's mean. There had been used three control variables: industrial concentration index, GDP growth and firm's size. The hypothesis that the market share, in Brazilian firms, has statistic significant temporal relation on residual income series, with Ohlson's LID persistence maintained is tested. The sample is collected from Economatica data base, including the period of 1996 - 2005. The results show that the LID premise is confirmed while the market share does not present informational content, as its coefficient $(B)$ is not statistically significant in all models processed. Facing these results, the research hypothesis is rejected. It's concluded that the market share, according to how it is measured in this study, does not cause abnormal gains in Brazilian firms based on the analysis of its residual profits.

Key words: persistence of residual income; Ohlson's model; fundamentalist analysis 


\section{INTRODUÇÃO}

A relevância de informações contábeis para a avaliação da firma tem sido reconhecida no âmbito da análise fundamentalista para avaliação da firma (HOLTHAUSEN; WATTS, 2001; BARTH; BEAVER; LANDSMAN, 2001; KOTHARI, 2001). Particularmente, o modelo de avaliação através do lucro residual proposto por Ohlson (1995) tem recebido ampla atenção dos pesquisadores (DECHOW; HUTTON; SLOAN, 1999; WALKER E WANG, 2003; LOPES, 2001; LOPES; TEIXEIRA, 2003).

A principal vantagem do modelo de avaliação de Ohlson (1995), e que o torna atrativo para pesquisas empíricas, é que o valor da firma pode ser estimado através do lucro residual. Para tanto, o modelo precisa atender a certas premissas.

De particular importância para o desenvolvimento deste estudo é a premissa de Dinâmica Informacional Linear, que permite a previsão do lucro residual do período seguinte a partir do lucro residual do período atual e de "outras informações" que não estejam ainda refletidas nos dados contábeis.

“Outras informações" captariam toda informação não contábil usada na predição de lucros anormais futuros (OHLSON, 1995), inclusive dados de indústria (por exemplo, participação de mercado) e dados macroeconômicos (por exemplo, crescimento do PIB).

"Outras informações" resumiriam, assim, eventos relevantes que ainda terão impacto nas demonstrações financeiras, sendo que esse conjunto de informações provoca impacto no lucro residual futuro, sem depender dos lucros residuais do passado (LOPES, 2002).

A potencial relevância do item "outras informações", comumente negligenciada na literatura empírica (OHLSON, 1995; HAND, 2001), reside tanto em um aumento no conteúdo empírico do modelo (OHLSON, 2001), quanto na aceitação de que não apenas dados contábeis publicamente disponíveis influenciam a avaliação da firma (HAND, 2001).

Esta pesquisa admite como uma provável fonte de "outras informações" os dados de indústria (por exemplo, a participação de mercado das firmas) e dados macroeconômicos (por exemplo, crescimento do PIB). O atual estudo se insere no âmbito da literatura que analisa empiricamente o modelo de avaliação através do lucro residual proposto por Ohlson (1995), enfatizando a premissa da DIL. Especificamente, incluem-se formalmente variáveis provenientes da literatura sobre economia industrial como "outras informações" no modelo de Ohlson (1995).

Investiga-se, portanto, o efeito da "participação de mercado de uma firma" como "outras informações" sobre a série futura de lucros residuais em firmas brasileiras, entendendo-se que os lucros anormais futuros seriam determinados também por fatores associados à concorrência econômica.

A literatura sobre economia industrial reconhece o efeito que a estrutura industrial tem sobre as estratégias competitivas disponíveis para as firmas, assim como seu efeito sobre os retornos obtidos na indústria, de modo que "a concorrência em uma indústria age continuamente no sentido de diminuir a taxa de retorno sobre o capital investido na direção da taxa competitiva básica de retorno" (PORTER, 2004, p. 5).

Reconhece-se, portanto, o efeito que o poder de mercado de uma indústria tem sobre a série de lucros residuais de uma firma. Entretanto, o efeito do grau de concentração de uma indústria sobre a persistência dos lucros residuais não é uniforme entre todas as empresas (PORTER, 2004). Cheng (2005) argumenta que o efeito do grau de concentração de uma indústria sobre a persistência dos lucros residuais é diferente do efeito do nível de competitividade das firmas sobre essa persistência (CHENG, 2005). 0 
grau de competitividade de uma firma pode ser medido como desempenho expresso pela sua participação de mercado no setor econômico em que ela atua.

A competitividade de uma firma, precisamente, as estratégias competitivas adotadas por ela, decorrem "de suas expectativas quanto às que lhe pareçam mais eficientes, mas só posteriormente o desempenho no mercado sancionará o acerto ou erro da escolha" (KUPFER, 1992, p. 4).

Uma vez que a competitividade de uma firma somente estará refletida em seu desempenho futuro, é de se esperar que seu grau de competitividade, medido por sua participação no mercado, represente "outras informações", ainda não refletidas na contabilidade, somente afetando lucros residuais futuros.

Testa-se, portanto, a hipótese de que a participação de mercado de uma firma tem um relacionamento temporal significante estatisticamente em sua série de lucros residuais, mantida a persistência da DIL de Ohlson (1995). Espera-se que firmas que atualmente apresentam maior participação de mercado e, conseqüentemente, maior competitividade, em decorrência de suas estratégias competitivas, apresentem maior persistência da série de lucros residuais, com sinais positivos.

O lucro residual é calculado a partir do modelo de avaliação de Ohlson (1995), enquanto a participação de mercado de cada firma será calculada como o percentual de sua receita líquida em relação à receita total do setor econômico do qual faça parte, ponderando-se pela representatividade desse setor em relação à média de todos os setores.

São utilizadas três variáveis de controle: índice de concentração industrial, crescimento do PIB e porte da firma. A amostra estudada é composta pelas firmas listadas no Economática que apresentam informações para cálculo do lucro residual em todos os períodos entre 1996-2005. Emprega-se a técnica de regressão com dados em painel.

0 principal diferencial deste estudo em relação a estudos anteriores e, portanto, sua principal contribuição em termos da pesquisa em contabilidade, é a inclusão da participação de mercado da firma como "outras informações" no modelo de avaliação da firma proposto por Ohlson (1995), indicando a influência que essa variável de economia industrial pode ter sobre o comportamento dos lucros residuais futuros.

Os resultados indicam que, em todos os modelos analisados, a persistência do lucro residual se mostra estatisticamente significante, de forma que variações nos lucros residuais antecedentes provocam variações positivas, portanto persistentes, nas variações dos lucros residuais subseqüentes. A hipótese de pesquisa relacionada à participação de mercado foi rejeitada em todas as suas versões.

0 restante deste artigo está estruturado como segue: na parte seguinte, as hipóteses são formuladas a partir do referencial teórico que discute tanto o modelo de avaliação da firma proposto por Ohlson (1995), quanto o conceito de competitividade; na terceira parte, os aspectos metodológicos incluem os procedimentos para seleção, coleta, processamento e análise dos dados; na quarta parte, realiza-se a análise de resultados; por fim, as conclusões são apresentadas. 


\section{REFERENCIAL TEÓRICO}

\subsection{MODELO DE AVALIAÇÃO DA FIRMA DE OHLSON (1995)}

O modelo de avaliação através do lucro residual proposto por Ohlson (1995) está fundamentado em três premissas:

i) $\quad 0$ valor presente dos dividendos esperados determina o valor intrínseco da firma;

ii) O lucro contábil satisfaz uma relação de lucro limpo (Clean Surplus Relation) e os dividendos reduzem o valor contábil do patrimônio líquido sem afetar os lucros atuais; e

iii) Existe uma ligação de persistência entre números contábeis contemporâneos e lucros residuais futuros - Dinâmica Informacional Linear (DIL).

Ohlson (1995) define o valor de uma firma $\left(\mathrm{P}_{\mathrm{t}}\right)$ como sendo a soma do valor contábil contemporâneo de seu patrimônio líquido $\left(\mathrm{y}_{\mathrm{t}}\right)$ e do valor presente dos lucros residuais futuros esperados $\left(x_{t+\tau}^{a}\right)$; em outras palavras, o valor de uma firma se iguala ao seu valor contábil ajustado pelo valor presente dos lucros residuais antecipados (1).

$$
P_{t}=y_{t}+\sum_{\tau=1}^{\infty} R f^{-\tau} E_{t}\left[x_{t+\tau}^{a}\right]
$$

O lucro residual, por sua vez, é estimado pela diferença entre o lucro contábil $\left(\mathrm{x}_{\mathrm{t}}\right)$ menos a remuneração do capital dos sócios, medida pela taxa de juros livre de risco ( $r$ ) multiplicada pelo valor contábil do patrimônio líquido no início do período (2).

$$
x_{t}^{a}=x_{t}-r\left(y_{t-1}\right)
$$

No que se refere especificamente à terceira premissa do modelo de avaliação proposto por Ohlson (1995), tem-se que a Dinâmica Informacional Linear assume que os lucros anormais seguem um processo estocástico de série de tempo auto-regressivo de ordem 1 - AR (1). De modo geral, modelos de informação linear permitem 0 desenvolvimento de modelos de avaliação baseados em dados contábeis que sejam empiricamente testáveis ao sugerir uma ligação entre números contábeis contemporâneos e lucros residuais futuros (MYERS, 1999).

Desse modo, a aceitação da premissa de Dinâmica Informacional Linear permite a previsão do lucro residual do período seguinte a partir do lucro residual do período atual e de outras informações que não estejam ainda refletidas nos dados contábeis.

Portanto, Ohlson (ano) admite em seu modelo que outras informações, além dos dados contábeis, influenciam a persistência dos lucros residuais, o que não interfere em serem estes os elementos principais da função de avaliação proposta.

Lucros residuais seguem, assim, uma seqüência linear de série de tempo em que lucros residuais na data $(\mathrm{t}+1)$ dependem dos lucros residuais na data $(\mathrm{t})$, mais uma correção para uma variável escalar que representa outras informações $\left(v_{t}\right)$ além dos dados contábeis (3).

$$
x_{t+1}^{a}=\omega x_{t}^{a}+v_{t}+\varepsilon_{1 t+1}
$$

Outras informações captariam toda informação não contábil usada na predição de lucros residuais futuros (OHLSON, 1995), inclusive dados de indústria (por exemplo,, nível de competitividade e participação de mercado) e dados macroeconômicos (por exemplo, crescimento do PIB), no âmbito de uma abordagem fundamentalista (OWENS, 2001). A 
variável "outras informações" também satisfaz um processo auto-regressivo de ordem 1 (4).

$$
v_{t+1}=\gamma v_{t}+\varepsilon_{2 t+1}
$$

Ohlson (1995) afirma que os termos de erro, $\varepsilon_{1 \tau}, \varepsilon_{2 \tau}$, sendo $\tau \geq 1$, são variáveis imprevisíveis, com média zero. Além disso, os parâmetros de persistência, $\omega$ e $\gamma$, são fixos e "conhecidos", com a restrição de que são não negativos e menores que 1 , o que torna possível a previsão do lucro residual do período seguinte a partir do lucro residual do período atual e de outras informações, dada sua estacionariedade, pois de outra forma o que se obteria seria um comportamento random walk (passeio aleatório) dos lucros residuais.

Este aspecto é de fundamental importância para o modelo de avaliação proposto, ou seja, a não aceitação da premissa de Dinâmica Informacional Linear dificulta a previsão dos lucros residuais e, conseqüentemente, a estimativa do valor da firma.

"Outras informações" $\left(\mathrm{v}_{\mathrm{t}}\right)$ deveriam ser pensadas como sumarizando eventos de valor relevante que ainda provocarão impacto sobre as demonstrações financeiras, sendo que esse conjunto de informações provoca impacto no lucro residual futuro, sem depender dos lucros residuais do passado.

Tal informação resulta em lucros residuais futuros independentemente de lucros residuais passados e contemporâneos, os quais já estarão captados na variável "Patrimônio Líquido". O modelo também implica que as realizações de $v_{t}$ (ou $\left.\varepsilon_{2 \tau}\right)$ não podem "evitar" as demonstrações financeiras, ou seja, ainda que com uma defasagem temporal, outras informações estarão contidas nas demonstrações financeiras.

Tem-se ainda que maiores valores dos parâmetros de persistência aumentam a permanência de longo prazo de lucros residuais, ou seja, quanto mais próximo de 1 estiver o parâmetro de persistência do lucro residual $(\omega)$, mais aquele lucro residual estará sendo refletido em períodos posteriores.

Lo e Lys (2000) mencionam que os parâmetros $\omega$ e $y$ são suficientes para diferenciar processos em que lucros são puramente transitórios de processos em que lucros são altamente persistentes. Entretanto, segundo afirmam Cupertino e Lustosa (2004), Ohlson não estabeleceu critérios para obter os parâmetros $\omega$ ou $\gamma$, restringindo-se a declarar que o meio econômico e os princípios contábeis da firma determinam os parâmetros exógenos $\omega$ e $\gamma$.

Portanto, o lucro residual do período seguinte dependerá tanto do parâmetro de persistência do lucro residual do período atual, quanto de outras informações, tais como aquelas relativas à estrutura da indústria e à estrutura macroeconômica. Por sua vez, a variável "outras informações" é independente, sendo função apenas de outras informações de períodos anteriores.

Um importante aspecto do modelo de Ohlson (1995), assim como outros modelos de avaliação, diz respeito à Hipótese de Eficiência de Mercado. Para que lucros anormais possam existir e, conseqüentemente, para que os investidores possam obter ganhos anormais no futuro no mercado de ações, o mercado não pode funcionar em sua forma de eficiência forte; em tal acepção não existem ganhos anormais mesmo com a presença de informações privilegiadas, tendo em vista que todas as informações relevantes (públicas ou não) já estariam refletidas no preço das ações (CARDOSO \& MARTINS, 2004).

Para a validade do modelo de Ohlson, portanto, a expectativa é de que o mercado funcione, por hipótese, em sua forma de eficiência semi-forte, em que não é possível a obtenção de ganhos anormais a partir das informações publicamente disponíveis (contábeis ou derivadas de outras fontes), mas apenas a partir de informações privilegiadas que 
somente serão captados por dados contábeis futuros. O modelo de mercado com a hipótese de eficiência semi-forte tem sido comumente aceito como válido no meio acadêmico.

A presença de "Outras Informações", públicas e não captadas ainda na contabilidade, objeto da presente pesquisa, corrobora a hipótese da eficiência semi-forte para o Modelo de Ohlson (1995), eis que se exige que as mesmas tenham impactado os preços sem terem ainda sido reconhecidas contabilmente por força dos princípios contábeis.

Diversos estudos têm testado empiricamente o modelo de avaliação da firma por meio do lucro residual proposto por Ohlson (1995), dentre os quais, podem ser citados os estudos de Dechow, Hutton e Sloan, 1999; Walker e Wang, 2003; Monahan, 2005; Choi, O'Hanlon e Pope, 2006. No Brasil, também tem sido razoável a quantidade de estudos que testam empiricamente o modelo de avaliação da firma através do lucro residual (por exemplo, LOPES, 2001; LOPES \& TEIXEIRA, 2003; SANT'ANNA; LOUZADA \& COSTA, 2005; GALDI \& LOPES, 2006).

Entretanto, até 1998, estudos que utilizavam o modelo de Ohlson (1995) não davam atenção ao conteúdo informacional de outras informações e os poucos que incluíram outras variáveis, fizeram isso de maneira intuitiva, ao invés de formalmente (HAND, 2001). No Brasil, outras informações permanecem sendo negligenciadas na utilização do modelo.

Ohlson (2001) argumenta que não incluir a variável "outras informações" no modelo, ou considerá-la de valor nulo, ainda que possa ser de interesse analítico, reduz o conteúdo empírico do modelo. Hand (2001) acrescenta que estabelecer um valor nulo para a variável "outras informações" equivale a assumir que somente dados contábeis publicamente disponíveis influenciam a avaliação da firma.

Ohlson (2001) afirma ainda que a razão principal para que a variável "outras informações" não seja considerada nos testes empíricos de seu modelo decorre do fato de ela não ser especificada.

Portanto, este estudo investiga a premissa de Dinâmica Informacional Linear do modelo de avaliação de Ohlson (1995), de modo a se constatar e possibilitar a estimativa do lucro residual, com a inclusão da participação de mercado da firma como "outras informações"; admite-se, assim, que a participação de mercado da firma será refletida na contabilidade futura.

\subsection{ANÁLISE ESTRUTURAL DE INDÚSTRIAS - COMPETITIVIDADE}

Porter (2004, p. 3) afirma que a indústria é o aspecto principal do meio-ambiente das firmas que competem entre si e que "[...] a estrutura industrial tem uma forte influência na determinação das regras competitivas do jogo, assim como das estratégias potencialmente disponíveis para a empresa".

Porter (2004) argumenta, ainda, que a concorrência em uma indústria provoca impactos na taxa de retorno sobre o capital investido, no sentido de reduzi-la continuamente em direção à taxa competitiva básica de retorno ou o retorno que seria obtido em uma indústria de concorrência perfeita.

Em outras palavras, pode-se afirmar que a concorrência em uma indústria faz com que o lucro residual dessa indústria tenda a zero ou que seu grau de persistência seja menor do que em indústrias cuja concorrência não é perfeita, no sentido de haver concentração. Ele menciona que a presença de taxas de retorno superiores à taxa competitiva básica de retorno estimula a entrada de novos capitais em uma indústria, seja 
essa entrada provocada por novas firmas entrantes, seja provocada pelas firmas já existentes na indústria.

Porter adiciona que "[...] o conjunto das forças competitivas em uma indústria determina até que ponto esse influxo de investimento ocorre e direciona o retorno para o nível da taxa de mercado livre e, assim, a capacidades das empresas de manterem retornos acima da média" (p. 5).

Porter (2004) enumera as seguintes cinco forças competitivas básicas que refletem que a concorrência não está limitada às firmas já existentes na indústria: entrantes potenciais, compradores, fornecedores, substitutos e concorrentes na indústria. 0 autor considera que essas forças competitivas básicas determinam o potencial de lucro final de uma indústria, sendo esse potencial medido em termos do retorno de longo prazo sobre o capital investido.

Entretanto, Porter argumenta que as forças externas que atuam sobre a indústria, afetando todas as firmas dessa indústria, têm que ser entendidas em sentido relativo, mais precisamente, em como cada firma lida com essas forças. Diante desse argumento, Porter (2004, p. 4) sentencia que a meta da estratégia competitiva para uma firma em uma indústria "[...] é encontrar uma posição dentro dela em que a companhia possa melhor se defender contra essas forças competitivas ou influenciá-las em seu favor”.

Portanto, é de se esperar que diferentes firmas tenham diferentes reações às forças externas que atuam sobre determinada indústria, logo tenham diferentes participações nos lucros residuais existentes em uma indústria. Precisamente, é de se esperar que o efeito do grau de concentração de uma indústria sobre a persistência dos lucros residuais seja diferente do efeito do nível de competitividade das firmas sobre essa persistência (CHENG, 2005).

Tem-se ainda que o efeito do grau de participação de uma firma sobre os lucros residuais não é imediato, ao contrário, trata-se de um fenômeno ex-post. Kupfer (1992, p. 4) menciona que o grau de competitividade de uma firma, que pode ser medido como desempenho expresso pela sua participação de mercado no setor econômico, decorre "de suas expectativas quanto às que lhe pareçam mais eficientes, mas só posteriormente o desempenho no mercado sancionará o acerto ou erro da escolha".

Diante dos argumentos de Cheng (2005) e de Kupfer (1992), este estudo investiga a seguinte hipótese de pesquisa:

H1: A participação de mercado atual de uma firma tem relacionamento temporal positivo e estatisticamente significante sobre a série de lucros residuais dessa firma, mantida a persistência da DIL de Ohlson (1995).

Diante dessa hipótese, espera-se um relacionamento positivo entre a persistência dos lucros residuais de uma firma e sua participação de mercado, de forma que firmas que atualmente apresentam maior participação de mercado e, conseqüentemente, maior competitividade, em decorrência de suas estratégias competitivas, apresentem maior persistência da série de lucros residuais, com sinais positivos.

Confirmando-se a hipótese deste estudo, será possível afirmar que firmas que atualmente apresentam maior participação de mercado somente terão esse desempenho refletido nos lucros residuais futuros, sendo maior a persistência desse lucro no futuro, quanto maior for a participação atual de mercado. 


\section{METODOLOGIA}

\subsection{PROCEDIMENTOS PARA SELEÇÃO, COLETA, PROCESSAMENTO E ANÁLISE dOS DADOS}

Este estudo selecionou as firmas que fazem parte do banco de dados do “Economática". Das 577 firmas disponíveis, compuseram a amostra 135 firmas. A razão para a exclusão das demais foi a ausência de dados em todos os anos entre os períodos de 1995 - 2005. O ano de 1995 foi incluído de modo a permitir as estimativas para o lucro residual de 1996. Assim, o período efetivamente adotado para a análise foi o de 1996 2005.

Foram coletadas, para cada firma, informações relativas a: i) patrimônio líquido, ii) lucro líquido; iii) receita líquida e iv) ativo total. A partir das duas primeiras informações, tornou-se possível o cálculo do lucro residual para cada firma, em cada um dos dez períodos analisados. Para tanto, utilizou-se a equação (2).

Para estimar o parâmetro de persistência do lucro residual de cada firma e o coeficiente da participação de mercado (B), utilizou-se análise de dados em painel por meio do pacote estatístico STATA. Foi utilizado o método que combina todos os dados em corte transversal e em séries temporais para estimar o modelo usando mínimos quadrados ordinários. Este modelo é considerado adequado quando a amostra é composta de firmas diferentes (GUJARATI, 2006).

Ademais, foi testada a influência de variáveis não observáveis, seja por efeitos fixos, seja por efeitos aleatórios, usando-se para a análise final a relação estatística mais adequada.

Para estimação dos parâmetros de interesse (persistência do lucro residual $(\omega)$ e impacto da participação de mercado $(B)$ ), foram realizados testes seqüenciais, utilizandose análise de dados em painel tanto estática quanto dinâmica, testando-se a influência de variáveis não observáveis; por efeitos fixos, por efeitos aleatórios, por primeiras diferenças e, ao final, pelo modelo dinâmico de Arellano-Bond (WOOLDRIDGE, 2002), de modo a explicitar relação econométrica consistente e eficiente.

Os resultados satisfatórios, do ponto de vista estrutural, decorreram do uso do modelo GMM de Arellano-Bond, já que $E\left(\varepsilon_{t+1} \mid x_{t+1}^{a}\right) \neq 0$ pela condição de defasagem entre as variáveis dependente e independente.

\subsection{MENSURAÇÃO DAS VARIÁVEIS}

O lucro residual foi calculado conforme proposto por Ohlson (1995), fazendo-se uso da equação (2), em que o lucro residual é estimado pela diferença entre o lucro contábil menos a remuneração do capital medida pela taxa de juros livre de risco multiplicada pelo valor contábil do patrimônio líquido no início do período. Como taxa de juros livre de risco, adotou-se o rendimento anual da poupança, segundo informações contidas na base de dados do Portal Brasil $囚$.

A participação de mercado de uma firma em determinado período $\left(M S_{i t}\right)$ foi definida como a razão entre suas vendas do período e as vendas totais do setor do qual participa naquele mesmo período. De modo a permitir a comparabilidade entre as participações de 
mercado de firmas que atuam em diferentes setores, fez-se uma ponderação da participação de mercado de uma firma pela representatividade do setor em relação à média dos setores.

O cálculo da representatividade do setor em relação à média dos setores, em cada período incluído na amostra, envolveu dois passos:

i. Cálculo da receita líquida setorial média - receita líquida total, calculada pelo somatório da receita líquida de todas as firmas incluídas na amostra, dividida pelo número de setores que compuseram a amostra (17 setores);

ii. Cálculo do quociente entre a receita líquida setorial (somatório da receita líquida de todas as firmas que compõem um determinado setor) pela receita líquida setorial média. Esse valor foi então empregado como fator de ponderação.

Foram incluídas três variáveis de controle: índice de concentração industrial, crescimento anual do PIB - segundo dados do IBGE - e porte da firma, calculado com base no volume de vendas (receita líquida).

A concentração industrial foi calculada através do índice de Hirschman-Herfindahl $(\mathrm{IHH})$. Para o cálculo do $\mathrm{IHH}$, realiza-se o somatório do quadrado da participação de mercado $\left(\mathrm{S}_{\mathrm{i}}\right)$ de todas as firmas no mercado - $\mathrm{IHH}=\sum_{i}\left(S_{i}\right)^{2}$.

O mercado total foi definido pelo somatório da receita líquida de vendas de todas as firmas participantes de um determinado setor com dados disponíveis no "Economática" (BESANKO; DRANOVE \& SHANLEY, 2000). passos:

Sendo assim, para o cálculo do IHH de cada setor, foram seguidos os seguintes

i) Realizou-se o somatório da receita líquida de vendas de todas as firmas que compõem um determinado setor, com a restrição de incluir apenas as firmas com dados disponíveis no "Economática";

ii) para cada setor, identificou-se a participação da receita líquida de vendas de cada firma em relação ao somatório realizado no passo anterior;

iii) para cada setor, elevou-se ao quadrado a participação de mercado de cada firma; e

iv) para cada setor, realizou-se o somatório do quadrado da participação de mercado de cada firma de modo a se chegar ao Índice de Concentração Industrial (IHH).

\subsection{MODELOS DE ANÁLISE}

Especificamente, foram testados os seguintes modelos, aos quais foram adicionadas, como variáveis de controle, dummies representativas dos anos:

i) Inicialmente, avaliou-se apenas a representatividade estatística do parâmetro de persistência $(\omega)$, ou seja, se o mesmo é significante estatisticamente e se está localizado entre zero e 1 (5);

$x_{t+1}^{a}=\alpha+\varpi x_{t}^{a}+\varepsilon_{t+1}$

ii) 0 segundo passo foi o processamento do modelo (5), controlado pelo volume de vendas, no sentido de examinar a relevância do porte da firma para "outras informações" (5a);

$$
x_{t+1}^{a}=\alpha+\varpi x_{t}^{a}+\delta_{3} \text { Vendas }_{t+1}+\varepsilon_{t+1}
$$


iii) Em seguida, foram inclusas as três variáveis de controle de modo a retirar o efeito que possivelmente provocam sobre o parâmetro de persistência (5b);

$x_{t+1}^{a}=\alpha+\varpi x_{t}^{a}+\delta_{1} I H H_{t}+\delta_{2} \Delta P I B_{t}+\delta_{3}$ Vendas $_{t+1}+\varepsilon_{t+1}$

iv) A partir do modelo (5), incluiu-se a participação de mercado de modo a avaliar se essa variável apresenta conteúdo informacional, ou seja, se o coeficiente da participação de mercado $(\theta)$ é positivo e significante estatisticamente (6);

$$
x_{t+1}^{a}=\alpha+\varpi x_{t}^{a}+\theta M S_{t}+\varepsilon_{t+1}
$$

v) Também se processou tal modelo, controlando apenas pelas vendas das empresas (6a);

$$
x_{t+1}^{a}=\alpha+\varpi x_{t}^{a}+\theta M S_{t}+\delta \text { Vendas }_{t+1}+\varepsilon_{t+1}
$$

vi) No modelo seguinte, adicionam-se ao modelo (7) as três variáveis de controle (6b);

$$
x_{t+1}^{a}=\alpha+\omega x_{t}^{a}+\theta M S_{t}+\delta_{1} I H H_{t}+\delta_{2} \Delta P I B_{t}+\delta_{3} \text { Vendas }_{t+1}+\varepsilon_{t+1}
$$

As variáveis MS (participação de mercado), IHH (índice de concentração industrial) e $\triangle P I B$ (taxa de crescimento do PIB) são apresentadas em termos percentuais. As demais variáveis representam valores absolutos em reais. Para tentar eliminar o efeito escala dessas variáveis em relação às que estão representadas em termos percentuais, elas são divididas pelo ativo total do início do período em todos os quatro modelos.

\section{ANÁLISE E DISCUSSÃO DOS RESULTADOS}

\subsection{ESCOLHA DO MÉTODO DE REGRESSÃO}

O passo inicial para a análise dos resultados foi a seleção do método de regressão adequado ao processamento dos dados, com o intuito de identificar parâmetros com características de consistência e eficiência. Para tanto, foram realizados os testes listados no Quadro 1.

Como em todos os modelos foi constatada a presença de heterocedasticidade, a qual compromete a eficiência dos estimadores, usaram-se matrizes de variâncias robustas em todos os modelos; por outro lado, em geral, foram detectadas variáveis omitidas, o que implica em inconsistência nos estimadores MQO; por isso foram testados os métodos usando dados em painel que consideram a presença de componentes não observáveis. 
Quadro 1 - Testes Econométricos realizados

\begin{tabular}{|l|l|}
\hline \multicolumn{1}{|c|}{ Testes } & \multicolumn{1}{c}{ Avaliação Efetuada } \\
\hline Breusch-Pagan/Cook Weisberg & $\begin{array}{l}\text { Avalia a presença de Heterocedasticidade na distribuição dos } \\
\text { resíduos da regressão por mínimos quadrados ordinários (MQO) }\end{array}$ \\
\hline Ramsey reset & Testa a existência de Variáveis Omitidas no Modelo considerado \\
\hline Breusch-Pagan & $\begin{array}{l}\text { Examina se a Variância dos Erros é igual a zero. Se tal Hipótese } \\
\text { for rejeitada, escolhe os resultados gerados pelo método de } \\
\text { Efeitos Aleatórios em contraposição a MQO }\end{array}$ \\
\hline Teste F - Efeitos Fixos & $\begin{array}{l}\text { Examina a Hipótese de significância dos coeficientes gerados pelo } \\
\text { método dos Efeitos Fixos }\end{array}$ \\
\hline Hausman & $\begin{array}{l}\text { Teste para escolha do método mais consistente e eficiente entre } \\
\text { Efeitos Aleatórios e Efeitos Fixos }\end{array}$ \\
\hline Autocorrelação dos resíduos & $\begin{array}{l}\text { Teste da presença de autocorrelação pela regressão entre os } \\
\text { resíduos estimados (usados em caso de regressões com variáveis } \\
\text { defasadas }\end{array}$ \\
\hline Teste Sargan & $\begin{array}{l}\text { Teste de correlação entre variáveis instrumentais e erros } \\
\text { estimados; examina se há sobre identificação de Instrumentos }\end{array}$ \\
\hline
\end{tabular}

Nessa etapa, então, os modelos foram processados utilizando-se as técnicas de painel estático - Efeitos Fixos e Efeitos Aleatórios - cujos testes de identificação ( $F$ Efeitos Fixos; Breusch-Pagan e Hausman) apresentaram resultados contraditórios, conduzindo a decisão para métodos de painel dinâmico, tendo em vista tratar-se de variável dependente defasada.

A aplicação de Primeiras Diferenças resultou no reconhecimento de autocorrelação serial; assim, conduziu-se para o teste final usando variáveis instrumentais em painel, conforme o método de Arellano-Bond. Trata-se de técnica usando GMM (Generalized Method of Moments), método que assume correção para a identificação genérica do modelo. Ressalte-se, ainda, que os instrumentos se demonstraram adequados, conforme indicações do teste de Sargan, o qual examina a identificação do modelo, pela análise da correlação entre as variáveis instrumentais e o erro estimado.

Como anotado acima, todos os coeficientes identificados para análise serão aqueles estimados por GMM - painel dinâmico.

\subsection{ANÁLISE DA PERSISTÊNCIA DOS LUCROS RESIDUAIS}

O passo seguinte corresponde à análise da significância dos parâmetros de persistência sem a inclusão de "outras informações". Foram relacionados na Tabela 1 os parâmetros de persistência da premissa de Ohlson (1995), bem como sua significância estatística e poder explicativo, estimados segundo os três modelos propostos (5, 5a e 5b) adicionados de dummies que captassem efeitos não observáveis relacionados aos períodos considerados. 
Percebe-se que os parâmetros estimados pelos modelos testados apresentam resultados semelhantes, todos estatisticamente significantes; interpreta-se então que variações nos lucros residuais antecedentes provocam variações positivas, portanto, persistentes, em torno de $21 \%$ nas variações dos lucros residuais subseqüentes.

As variáveis de controle adicionadas ao modelo (porte da firma, índice de concentração industrial e variações do PIB) não parecem afetar a persistência dos lucros anormais, não se podendo, portanto, atribuir interferência do volume de vendas sobre a série de lucros residuais, bem como referir-se a impacto das demais variáveis de controle.

Tabela 1 - Coeficientes de Persistência

\begin{tabular}{|c|c|c|c|c|c|c|c|}
\hline & & & & & IÉTODOS & & \\
\hline & MODELOS & MQO & $\begin{array}{l}\text { Efeitos } \\
\text { Aleatórios }\end{array}$ & $\begin{array}{c}\text { Efeitos } \\
\text { Fixos }\end{array}$ & $\begin{array}{l}\text { Primeiras } \\
\text { Diferenças }\end{array}$ & $2 S L S$ & $\begin{array}{c}\text { GMM } \\
\text { (Arellano-Bond) }\end{array}$ \\
\hline & $\begin{array}{l}\text { Coeficiente } \\
\omega\end{array}$ & 0.44 & 0.44 & 0.20 & -0.38 & 0.19 & 0.21 \\
\hline 5 & Teste $\mathrm{z} / \mathrm{t}$ & 5.95 & 5.95 & 2.27 & -4.57 & 11.15 & 2.08 \\
\hline & $\mathrm{R}^{2} /$ Wald & $24 \%$ & 434.49 & $20 \%$ & $15 \%$ & 548.28 & 88.43 \\
\hline & $\begin{array}{l}\text { Coeficiente } \\
\omega\end{array}$ & 0.43 & 0.43 & 0.19 & -0.37 & 0.19 & 0.21 \\
\hline $5 a$ & Teste $\mathrm{z} / \mathrm{t}$ & 5.78 & 5.78 & 2.22 & -4.36 & 11.38 & 2.14 \\
\hline & $\mathrm{R}^{2} /$ Wald & $24 \%$ & 475.31 & $14 \%$ & $15 \%$ & 608.79 & 96.16 \\
\hline & $\begin{array}{l}\text { Coeficiente } \\
\omega\end{array}$ & 0.43 & 0.43 & 0.19 & -0.37 & 0.19 & 0.21 \\
\hline $5 b$ & Teste $z / t$ & 5.75 & 5.75 & 2.22 & -4.35 & 10.97 & 2.18 \\
\hline & $\mathrm{R}^{2} /$ Wald & $25 \%$ & 474.24 & $14 \%$ & $15 \%$ & 621.71 & 97.49 \\
\hline
\end{tabular}

\subsection{PARTICIPAÇÃO DE MERCADO E PERSISTÊNCIA DOS LUCROS RESIDUAIS}

A segunda hipótese de pesquisa prevê que a participação de mercado atual de uma firma tem relacionamento temporal positivo e estatisticamente significante sobre a série de lucros residuais dessa firma, mantida a persistência da DIL de Ohlson (1995).

Foram relacionados, na Tabela 2 , os parâmetros de persistência da premissa de Ohlson (1995), bem como sua significância estatística e poder explicativo, incluindo o efeito da participação de mercado. As estimativas consideram os três modelos propostos que incluem participação de mercado como "outras informações" (6, 6a e 6b), adicionados de dummies que captassem efeitos não observáveis relacionados aos períodos considerados. 
Percebe-se novamente que os parâmetros de persistência estimados pelos três modelos testados são estatisticamente significantes, com poder explicativo em torno de $22 \%$.

Tabela 2 - Coeficientes de Persistência e Participação de Mercado

\begin{tabular}{|c|c|c|c|c|c|c|}
\hline & \multirow[b]{2}{*}{ MODELOS } & \multicolumn{5}{|c|}{ MÉTODOS } \\
\hline & & MQO & $\begin{array}{c}\text { Efeitos } \\
\text { Aleatórios }\end{array}$ & Efeitos Fixos & $\begin{array}{l}\text { Primeiras } \\
\text { Diferenças }\end{array}$ & $\begin{array}{c}\text { GMM } \\
\text { (Arellano-Bond) }\end{array}$ \\
\hline \multirow{3}{*}{7} & $\begin{array}{l}\text { Coeficiente } \\
\omega\end{array}$ & 0.43 & 0.43 & 0.20 & -0.38 & 0.22 \\
\hline & Teste $t$ & 5.81 & 5.81 & 2.25 & -4.57 & 2.13 \\
\hline & $\mathrm{R}^{2} /$ Wald & $24 \%$ & 456.36 & $21 \%$ & $15 \%$ & 89.89 \\
\hline \multirow{3}{*}{$7 a$} & $\begin{array}{l}\text { Coeficiente } \\
\omega\end{array}$ & 0.42 & 0.42 & 0.19 & -0.38 & 0.22 \\
\hline & Teste $t$ & 5.66 & 5.66 & 2.21 & -4.36 & 2.19 \\
\hline & $\mathrm{R}^{2} /$ Wald & $25 \%$ & 496.39 & $14 \%$ & $15 \%$ & 98.27 \\
\hline \multirow{3}{*}{$7 \mathrm{~b}$} & $\begin{array}{l}\text { Coeficiente } \\
\omega\end{array}$ & 0.42 & 0.42 & 0.19 & -0.37 & 0.22 \\
\hline & Teste $t$ & 5.65 & 5.65 & 2.21 & -4.35 & 2.22 \\
\hline & $\mathrm{R}^{2} /$ Wald & $25 \%$ & 497.19 & $14 \%$ & $15 \%$ & 98.64 \\
\hline
\end{tabular}

A hipótese de que a participação de mercado das firmas possa impactar a trajetória futura dos lucros anormais é rejeitada (também aos níveis usuais de significância estatística). Tal conclusão se depreende da análise da Tabela 3, na qual são listados os coeficientes associados à variável representativa da participação de mercado (MS) de cada modelo com o respectivo teste de significância; mostra-se que a parcela de mercado, além de não alterar os coeficientes de persistência dos lucros anormais, relaciona-se negativamente com a série de lucros futuros em desacordo com a teoria considerada para esses testes.

Tabela 3 - Coeficientes B - Participação de Mercado (Processado pelo GMM/Arellano-Bond)

\begin{tabular}{c|c|c|c|c|}
\hline MODELOS & Coeficiente $\omega$ & Teste $z$ & Coeficiente $B$ & Teste $z$ \\
\hline 7 & 0.22 & 2.13 & -0.025 & -0.71 \\
\hline $7^{a}$ & 0.22 & 2.19 & -0.039 & -0.84 \\
\hline $7 b$ & 0.22 & 2.22 & -0.023 & -0.56 \\
\hline
\end{tabular}


Diante desses resultados, não se aceita a hipótese de pesquisa de que participação de mercado, em firmas brasileiras, tem um relacionamento temporal significante estatisticamente em sua série de lucros residuais, mantida a persistência da DIL de Ohlson, já que a inclusão da participação de mercado, proxy para a competitividade de uma firma, não apresenta conteúdo informacional, tendo em vista que os coeficientes (B) não são estatisticamente diferentes de zero.

\section{CONSIDERAÇÕES FINAIS}

Partindo da premissa da Dinâmica Informacional Linear do modelo de avaliação de Ohlson (1995), assim como, da premissa de que o nível atual de competitividade de uma firma somente estará refletido em lucros residuais futuros, este estudo teve o objetivo de analisar a Dinâmica Informacional Linear de Ohlson, avaliando, especificamente, os efeitos da competitividade de firmas brasileiras sobre a série de lucros residuais.

Os resultados demonstraram que o parâmetro de persistência $(\omega)$ é significante estatisticamente e está dentro do intervalo entre zero e 1, conforme sugerido pela premissa da Dinâmica Informacional Linear.

Observou-se, por outro lado, que a inclusão da participação de mercado, proxy para a competitividade de uma firma, não apresentou conteúdo informacional ao modelo de avaliação da firma de Ohlson, sendo estatisticamente igual a zero seu coeficiente (B).

Desse modo, rejeita-se a hipótese de pesquisa de que a participação de mercado, em firmas brasileiras, tem um relacionamento temporal significante estatisticamente em sua série de lucros residuais, mantida a persistência da Dinâmica Informacional Linear de Ohlson.

Tem-se ainda que a maior parte das firmas presentes na amostra em estudo não domina o mercado em que atuam, confirmado tanto por sua participação de mercado quanto pelo Índice Hirschman-Herfindahl, sugerindo que o grau de concentração industrial também não é fator preditivo para persistência da série de lucros anormais.

Diante desses resultados, conclui-se que a participação de mercado não provoca efeitos significantes estatisticamente sobre a série de lucros residuais em firmas brasileiras, quando incluída como "outras informações" no modelo de avaliação da firma de Ohlson. Contudo, a cautela com tais inferências se deve ao fato de que as informações utilizadas não contemplam o conjunto completo das empresas de cada indústria.

Embora a amostra selecionada seja representativa dos setores abordados, pois constituem as maiores firmas contidas nos setores - companhias de capital aberto de porte representativo -, o fato de não estarem confrontadas com o conjunto da economia pode determinar viés nos resultados apontados.

Sugere-se que futuras pesquisas reforcem a importância em se identificar e avaliar o efeito de outras variáveis sobre a série de lucros residuais. Variáveis tais como barreiras de entrada, barreiras de saída, concorrentes, fornecedores e substitutos podem potencialmente afetar a persistência de lucros residuais. A inclusão de tais variáveis permitiria a mudança do nível de análise que, neste estudo, enfatiza uma variável ao nível da firma, enquanto as variáveis mencionadas se localizam ao nível da indústria.

Adotando-se a mesma perspectiva do atual estudo, em que se pesquisa a existência de eventos econômicos não reconhecidos na contabilidade da firma no momento de sua 
ocorrência, geralmente em virtude do Princípio da Competência Contábil dos Exercícios, tais variáveis teriam, forçosamente, que ser representadas por proxies não contábeis, valendo dizer que tais fatores seriam captados pela contabilidade no futuro.

Também seria interessante que se consiga variável representativa da concorrência e da competitividade, inclusive em termos macroeconômicos ou ainda considerando na amostra companhias de capital fechado, que possa ser utilizada com a série de lucros residuais das firmas.

\section{REFERÊNCIAS}

BARTH, M. E.; BEAVER, W. H.; LANDSMAN, W. R. The relevance of the value relevance literature for financial accounting standard setting: another view. Journal of Accounting and Economics, v. 31, 2001, p. 77-104.

BESANKO, D.; DRANOVE, D.; SHANLEY, M. The economics of strategy. 2 ed. New York: John Wiley \& Sons, 2000.

CARDOSO, R. L.; MARTINS, V. A. Hipótese de mercado eficiente e modelo de precificação de ativos financeiros. In: IUDÍCIBUS, S.; LOPES, A. B. (Coord.). Teoria avançada da contabilidade. São Paulo: Atlas, 2004. p. 70-133.

CHENG, Q. What determines residual income. The Accounting Review, v. 80, n. 1, 2005, p. 85-112.

CHOI, Y., O'HANLON, J. F.; POPE, P. F. Conservative Accounting and Linear Information Valuation Models. Contemporary Accounting Research, v. 23, n. 1, 2006, p. 73.

CUPERTINO, C. M.; LUSTOSA, P. R. B. O modelo Ohlson de avaliação de empresas: tutorial para utilização. In: Congresso USP de Controladoria e Contabilidade, 4, 2004, São Paulo. 2004. Anais... São Paulo: USP, 2004.

DECHOW, P. M.; HUTTON A. P.; SLOAN R. G. An Empirical Assessment of the Residual Income Valuation Model. Journal of Accounting and Economics, v. 26, 1999, p. 1-34.

GALDI, F. C.; BROEDEL, A. B. Análise empírica de valuation no ambiente brasileiro: fluxo de caixa descontado versus modelo de Ohlson. In: ENANPAD, 30, 2006, Salvador. 2006. Anais... Salvador, 2006.

GUJARATI, D. N. Econometria Básica. 4. ed. Rio de Janeiro: Elsevier, 2006.

HAND, J. R. Discussion of Earnings, Book Values, and Dividends in Equity Valuation: An Empirical Perspective. Contemporary Accounting Research, v. 18, n. 1, 2001, p. 121-130.

HOLTHAUSEN, R. W.; WATTS, R. L. The relevance of the value-relevance literature for financial accounting standard setting. Journal of Accounting and Economics, v. 31, 2001, p. 3-75.

HOU, K; ROBINSON, D. T. Industry concentration and average stock returns. The Journal of Finance, v. LXI, n. 4, 2006. p. 1927-1956.

KOTHARI, S. P. Capital Markets Research in Accounting. Journal of Accounting and Economics, v. 31, 2001, p. 105-231.

KUPFER, D. Padrões de concorrência e competitividade. In: Encontro Nacional da ANPEC, XX, 1992. Anais... Campos do Jordão, 1992. 
LO, K.; LYS, T. The Ohlson model: contribution to valuation theory, limitations, and empirical applications. Journal of Accounting, Auditing and Finance, v. 15, 2000, p. 33767.

LOPES, A. B. A relevância da informação contábil para o mercado de capitais: o modelo de Ohlson aplicado à BOVESPA. 2001. Tese (Doutorado em Ciências Contábeis) Faculdade de Economia, Administração e Contabilidade, Universidade de São Paulo, São Paulo.

A Informação Contábil e o Mercado de Capitais. São Paulo: Pioneira Thomson, 2002.

.; TEIXEIRA, A. J. C. Valuation properties of accounting numbers in Brazil. ENANPAD, XXVII, Atibaia. Anais... Atibaia, 2003.

MONAHAN, S. J. Conservatism, growth and the role of accounting numbers in the fundamental analysis process. Review of Accounting Studies, v. 10, n. 2-3, 2005, p. 227260.

MYERS, J. N. Implementing Residual Income Valuation with Linear Information Dynamics. The Accounting Review, v. 74, 1999, p. 1-28.

OHLSON, J. A. Earnings, Book Values, and Dividends in Equity Valuation. Contemporary Accounting Research, v. 11, 1995, p. 661-687.

Earnings, book values, and dividends in equity valuation: an empirical perspective. Contemporary Accounting Research, v. 18, n. 1, 2001, p. 107-120.

OWENS, L. A. An examination of the relationships between strategy, environment, and performance in a fundamental analysis model. Oklahoma State University. December, 2001.

PORTER, M. E. Estratégia competitiva: técnicas para análise de indústrias e da concorrência. Rio de Janeiro: Campus, 2004.

SANT'ANNA, D. P.; LOUZADA, L. C.; COSTA, F. M. A relevância das informações contábeis na Bovespa a partir do arcabouço teórico de Ohlson: avaliação dos modelos de Residual Income Valuation e Abnormal Earnings Growth. ENANPAD, XXIX, 2005, Brasília. 2005. Anais... Brasília, 2005.

WALKER, M.; WANG, P. Towards an understanding of profitability analysis within the residual income valuation framework. Accounting and Business Research, v. 33, n. 3, 2003, p. 235.

WOOLDRIDGE, Jeffrey M. Econometric analysis of cross section and panel data. Cambridge: The MIT Press, 2002. 